[RESEARCH ARTICLE]

\title{
The effect of emotion regulation skills training on mental health, happiness, and organizational performance in employees
}

\author{
Reza Koushkestani ${ }^{1}$, Ali Nazeri Astaneh 2,*, Gita Sadighi 3, Zeinab Hajikhaniyan ${ }^{4}$, Alireza Zarandi 5 and \\ Alireza Motahedi 6 \\ ${ }^{1}$ Masters of Clinical Psychology, School of Psychology and Educational Sciences, South Branch, Islamic Azad University, \\ Tehran, Iran. \\ ${ }^{2}$ Associate Professor of Psychiatry, Psychosis Research Center, the University of Social Welfare and Rehabilitation \\ Sciences, Tehran, Iran. \\ ${ }^{3}$ Assistant Professor of Psychiatry, Department of Psychiatry, the University of Social Welfare and Rehabilitation Sciences, \\ Tehran, Iran. \\ ${ }^{4}$ Masters of Clinical Psychology, School of Psychology and Educational Sciences, South Branch, Islamic Azad University, \\ Tehran, Iran. \\ ${ }^{5} \mathrm{PhD}$ in Psychology. \\ ${ }^{6}$ Department of Psychology, Faculty of Humanities, Islamic Azad University of Varamin, Tehran, Iran.
}

Publication history: Received on 19 October 2020; revised on 28 October 2020; accepted on 30 October 2020

Article DOI: https://doi.org/10.30574/wjarr.2020.8.2.0388

\begin{abstract}
Background: Coping with negative emotions are of the everyday life challenges that all individuals encounter constantly. Employing efficient Emotion Regulation [ER] strategies could significantly influence individuals' quality of life and wellbeing. ER has also been targeted as a core process in the research and treatment of psychopathology. Accordingly, the present study aimed to examine the effects of an ER skills training program on mental health, happiness, and organizational performance in employees.
\end{abstract}

Methods: This was a quasi-experimental study with a pretest-posttest and a control group design. The statistical population of the present study consisted of the employees of the central offices of Bank Mellat [all of which are located in Tehran City, Iran] in April and May 2017 [N=2107]. According to Morgan's table for sample size, 40 individuals were calculated as the study participants. The experimental group received training for four weeks [two 90-min sessions per week]. Multivariate Analysis of Covariance [MANCOVA] was used to compare the two groups of control and training and eliminate the effect of the pretest. The obtained data were analyzed in SPSS at the significance level of $p<0.05$.

Results: A total of 40 individuals completed the intervention course. The age of the study subjects ranged between 28 and 50 years. The mean \pm SD age of the study participants in the training and control groups was $26.67 \pm 0.49$ and $26.89 \pm 0.57$ years, respectively. The Independent Samples t-test results indicated no significant difference in terms of age between the study groups. Furthermore, the MANCOVA data suggested that after controlling the pretest scores as a covariate variable, the provided emotion regulation training significantly improved the posttest scores of the study subjects $\left[p<0.05, \mathrm{~F}_{9.20}=-3.295\right]$.

Conclusion: ER training could play an essential role in reducing physical symptoms, anxiety, depression, and other mental health conditions by informing a person about positive and negative emotions, as well as accepting and expressing them in a timely manner. The present research findings highlighted the effectiveness of ER skills training on mental health, happiness, and organizational performance of the investigated employees. Accordingly, the significance

\footnotetext{
${ }^{*}$ Corresponding author: Ali Nazeri Astaneh; ORCID: 0000-0002-8458-8045; E-mail: drnazeri2019@gmail.com

Associate Professor of Psychiatry, Psychosis Research Center, the University of Social Welfare and Rehabilitation Sciences, Tehran, Iran.

Copyright (c) 2020 Author(s) retain the copyright of this article. This article is published under the terms of the Creative Commons Attribution Liscense 4.0.
} 
of ER skills training should be considered in improving mental health, happiness, and organizational performance among employees.

Keywords: Emotion Regulation Skills Training; Mental Health; Happiness; Organizational Performance

\section{Introduction}

Emotions are strongly associated with thoughts, behaviors, and experience, which could be regulated through multiple manners [1]. Emotion Regulation [ER] consists of various cognitive and attentional processes implemented to modify or sustain an emotional state [2]. Prior investigations highlighted the critical impact of ER strategies and ER impairments on the psychopathology context [3].

Coping with negative emotions are of the everyday life challenges that all individuals encounter constantly. Employing efficient ER strategies could significantly influence individuals' quality of life and wellbeing [4]. On the other hand, previous studies suggested that fostering ineffective ER methods are correlated with the generation and maintenance of numerous mental health conditions [5]. The literature signifies ER processes as a transdiagnostic characteristic to play essential roles in a wide range of mental health disorders [6-8]. ER is also suggested to be a crucial aspect in multiple models of mental health illnesses, such as major depressive disorder [9, 10], generalized anxiety disorder [11], borderline personality disorder [12-14], eating disorders [15-17], and bipolar disorder [18]. Effective ER ability could significantly be beneficial in treating various mental health issues [19].

The World Health Organization [WHO] defines mental health as a wellbeing state in which individuals recognize their abilities, could be productive, can contribute to the community, and can cope with daily living stresses [20].

A meta-analysis study explored the relationship between ER strategies [expressive suppression \& cognitive reappraisal] and mental health [negative affect, depression, anxiety, positive affect, \& life-satisfaction]. The relevant findings demonstrated while there was a significant and positive correlation between cognitive reappraisal and the positive indicators of mental health, the same was negatively associated with the negative indicators of mental health. In addition, there was an association between negative expressive suppression and the positive indicators of mental health; however, negative expressive suppression was positively correlated with the negative indicators of mental health. Accordingly, they suggested performing cohort examinations on the relationship between ER and mental health by controlling the impact of mediating variables in different populations [21].

Over the past 25 years, psychology has focused on the positive dimensions of life [22, 23] and numerous researchers have shown interest in these areas [24]. The history of overreaching happiness goes back to when Aristotle spoke of Eudaimonia [25]. Happiness is among the fundamental issues in positive psychology and refers to the experience of enhanced positive emotions and reduced negative emotions as well as having high life satisfaction [26]. According to this definition, positive and negative emotions include the emotional aspect of happiness and life satisfaction that constitute the cognitive dimension of happiness [27]. According to scholars, success and happiness result from ER, as re-evaluating emotions could alleviate the effects of negative emotions [28].

Furthermore, the organizational performance and cooperation of employees have been introduced as a positive emotional state [29]. In this respect, employee's ER, happiness, and mental health are among the effective characteristics of their organizational performance. Moreover, emotions and the manner of expressing them explain the significance of organizational and individual outputs [30]. Organizational performance is an indicator of understanding the path to achieving the goals of an organization or institution [31].

According to the literature, data on the impact of ER skills training on mental health, happiness, and organizational performance are scarce. Moreover, the ER has been targeted as a core process in the research and treatment of psychopathology [32]. Thus, the present study aimed to examine the effects of an ER skills training program on mental health, happiness, and organizational performance in employees.

\section{Material and methods}

This was a quasi-experimental study with a pretest-posttest and a control group design. The investigated variables were measured before and after providing the 8-week educational program. The statistical population of the present study consisted of the employees of the central offices of Bank Mellat [all of which are located in Tehran City, Iran] in April and May 2017 [N=2107]. According to Morgan's table for sample size, 40 individuals were calculated as the study 
participants. For this purpose, we employed a random simple sampling approach. Subsequently, the study subjects were randomly assigned to the experimental and control groups with 20 individuals per group. The experimental group received training for four weeks [two 90 -min sessions per week]. The pretest data were collected two days before the intervention, and the posttest data were obtained one month after the eighth session from both research groups.

The required data were collected applying the following scales:

The Symptom Checklist-90 [SCL-90]: This psychometric tool briefly investigates various mental health issues as well as psychopathology symptoms on a self-report basis. The reliability of this test was established by the test-retest method with the coefficients ranging from 0.78 to 0.90 . The structure validity of this scale also suggested it as a desirable tool to distinguish individuals with mental health disorders from the healthy population [33].

The Oxford Happiness Inventory [OHI]: This tool was designed by Argyle, Martin, and Crossland in 1989 as a comprehensive questionnaire of personal happiness in terms of emotional and cognitive aspects [34]. Moreover, Cronbach's alpha coefficient of 0.90 was calculated for it, reflecting the acceptable validity of this tool.

Allen and Meyer's Organizational Commitment Questionnaire [OCQ]: This scale was developed in 1987 and was employed in the present study to evaluate organizational performance. Previous assessments conducted in Iran supported the validity and reliability of this tool.

The content of the provided training sessions is briefly presented in Table 1.

Table 1 The content of emotion regulation skills training sessions

\begin{tabular}{|c|c|}
\hline Session & Content \\
\hline One & $\begin{array}{l}\text { Introducing ER and reflecting its importance, emotional schema therapy [techniques for } \\
\text { identifying emotional schemas, emotion normalization, examining emotions as goals, creating } \\
\text { space for emotion] }\end{array}$ \\
\hline Two & $\begin{array}{l}\text { Credibility training [credibility resistance techniques, identifying troublesome responses to } \\
\text { discredibility, developing more adaptive coping strategies to manage discredibility, } \\
\text { compassionate self-validation, and developing better friendships] }\end{array}$ \\
\hline Three & $\begin{array}{l}\text { Teaching dialectical behavior therapy skills for ER [identify and label emotions, } \\
\text { identify obstacles to changing emotions, reduce vulnerability to an emotional mind, increase } \\
\text { positive emotional events, increase mindfulness to current emotions, take opposite action, } \\
\text { apply distress tolerance techniques] }\end{array}$ \\
\hline Four & $\begin{array}{l}\text { Mindfulness training [body scanning techniques, mindful breathing, creating space and 3- } \\
\text { minute breathing space] }\end{array}$ \\
\hline Five & $\begin{array}{l}\text { Reviewing the exercises of the previous sessions and teaching acceptance and desire [the } \\
\text { techniques of defusion and using metaphor to cultivate desire and defusion] }\end{array}$ \\
\hline Six & $\begin{array}{l}\text { Reviewing the exercises of the previous sessions and emotional processing improvement } \\
\text { techniques [techniques for strengthening emotional awareness and a record of emotionally } \\
\text { intelligent thoughts] }\end{array}$ \\
\hline Seven & $\begin{array}{l}\text { Cognitive reconstruction training [techniques for discriminating thoughts from emotions, } \\
\text { categorizing negative thoughts, evaluating advantages and disadvantages, assessing } \\
\text { evidence, and decatastrophizing] }\end{array}$ \\
\hline Eight & $\begin{array}{l}\text { Stress reduction training [progressive muscle relaxation techniques, diaphragmatic } \\
\text { breathing, activity planning and pleasure prediction, time management and relaxation } \\
\text { techniques, and positive imaging] }\end{array}$ \\
\hline
\end{tabular}

Descriptive and inferential statistics were employed to analyze the collected data. Descriptive statistics included mean and standard deviation. Furthermore, Multivariate Analysis of Covariance [MANCOVA] was used to compare the two groups of control and training and eliminate the effect of the pretest. The obtained data were analyzed in SPSS at the significance level of $p<0.05$. 


\section{Results}

The present study results indicated that a total of 40 individuals completed the intervention course. The age of the study subjects ranged between 28 and 50 years. Furthermore, the youngest and oldest participants in the intervention group aged 28 and 51 years, respectively. Table 2 lists the group-wise frequency of the female and male participants and their academic achievement level.

According to Table 2 , the mean \pm SD age of the study participants in the training and control groups was $26.67 \pm 0.49$ and $26.89 \pm 0.57$ years, respectively; as a result, the Independent Samples t-test results indicated no significant difference in terms of age between the study groups.

Table 2 The demographic data of the study participants in the experimental and control groups

\begin{tabular}{|c|c|c|c|c|}
\hline \multicolumn{2}{|l|}{ Variable } & \multirow{2}{*}{$\begin{array}{l}\text { Training group } \\
{[\mathbf{n}=\mathbf{2 0}]} \\
13\end{array}$} & \multirow{2}{*}{$\begin{array}{l}\text { Control group } \\
{[\mathrm{n}=20]}\end{array}$} & \multirow{2}{*}{$\begin{array}{l}\text { Total } \\
{[\mathrm{N}=40]}\end{array}$} \\
\hline Gender & Male & & & \\
\hline & Female & 7 & 9 & \\
\hline \multirow{5}{*}{$\begin{array}{l}\text { Educational } \\
\text { level }\end{array}$} & High-school diploma & 5 & 1 & \\
\hline & Associate degree & 1 & 2 & \\
\hline & BA & 8 & 8 & \\
\hline & MA & 6 & 8 & \\
\hline & $\mathrm{PhD}$ & 0 & 1 & \\
\hline \multicolumn{2}{|c|}{ Age, $[$ mean $\pm S D]$} & $26.67 \pm 0.49$ & $26.89 \pm 0.57$ & $26.78 \pm 0.53$ \\
\hline
\end{tabular}

Mancova was implemented to test the main hypothesis of the research. The relevant results are presented in the following.

Table 3 The descriptive-comparative data of the study groups

\begin{tabular}{|l|l|l|l|l|}
\hline Variable & Group & Mean & SD & No. \\
\hline \multirow{4}{*}{ Mental health } & Control & 150.6842 & 44.85043 & 20 \\
\cline { 2 - 5 } & Training & 115.8500 & 18.15511 & 20 \\
\cline { 2 - 5 } & Total & 132.8205 & 37.79924 & 40 \\
\hline \multirow{4}{*}{ Happiness } & Control & 105.1053 & 20.71203 & 20 \\
\cline { 2 - 5 } & Training & 124.3500 & 24.29918 & 20 \\
\cline { 2 - 5 } $\begin{array}{l}\text { Organizational } \\
\text { performance }\end{array}$ & Total & 114.9744 & 24.35968 & 40 \\
\cline { 2 - 5 } & Control & 96.0000 & 16.98692 & 20 \\
\cline { 2 - 5 } & Training & 105.1000 & 13.18652 & 20 \\
\cline { 2 - 5 } & Total & 100.6667 & 15.64799 & 40 \\
\hline
\end{tabular}

The mancova data suggested that after controlling the pretest scores as a covariate variable, the provided emotion regulation training significantly improved the posttest scores $\left[p<0.05, \mathrm{~F}_{9.20}=-3.295\right]$. 
Table 4 The mancova data concerning the effect of er skills training on the study variables

\begin{tabular}{|l|l|l|l|l|}
\hline Variable & F & $\begin{array}{l}\text { Significance } \\
\text { level }\end{array}$ & Effect size & Test power \\
\hline Mental health & 14.265 & 0.001 & 0.296 & 0.956 \\
\hline Happiness & 11.985 & 0.001 & 0.261 & 0.920 \\
\hline $\begin{array}{l}\text { Organizational } \\
\text { performance }\end{array}$ & 3.996 & 0.054 & 0.105 & 0.493 \\
\hline
\end{tabular}

\section{Discussion}

Emotion regulation plays a critical role in healthy development. A poor ER is an essential factor in the generation of mental health disorders. Thus, scholars have paid special attention to the relationship between ER and biopsychological health in recent years. Furthermore, success and happiness have been addressed as a result of the ER. Re-evaluating emotion has been identified as an effective approach to reducing the impact of negative emotions on individuals. In addition, happy individuals enjoy better physical and mental health status as well as a longer life expectancy. Besides, they achieve higher professional and social success.

The present study results indicated that the provided ER skills training increased the extent of mental health and happiness in the explored employees; however, it failed to improve two dimensions of employee's organizational performance and only one aspect of it was enhanced. The current research findings on mental health were consistent with those of other studies, including Mennin et al. [35], Berking et al. [36], as well as Garnefski, and Kraaij [37]. All these studies supported the effect of ER skills training on improving mental health status. In other words, ER skills training enables individuals to cope with negative emotions more adaptively and be exposed to less mental health conditions. Difficulty in ER is associated with numerous psychiatric disorders; therefore, the ER process is increasingly incorporated into the patterns of psychopathology.

In addition to positive impacts on mental well-being, ER skills training also improved physical health; accordingly, difficulty in regulating emotions leads to physical problems. A poor ER is associated with numerous psychiatric disorders classified in the Diagnostic and Statistical Manual of Mental Disorders [DSM].

Another finding of the present research was that the presented ER skills training enhanced individuals' happiness level, i.e., consistent with other studies, such as Brans et al. [38], Webb et al. [39], as well as Graz and Ganderson [40]. Mental health is defined as the ability of an individual to adapting to the surrounding world to the highest possible extent, resulting in happiness as well as fostering a beneficial and effective perception; thus, the effect of mental health on happiness was supported in this research. Success and happiness result from ER, and re-evaluating emotions is an approach to reduce the effects of negative emotions, i.e., considered a sign of happiness.

According to the obtained data, the provided ER skills training has improved all components of mental health. These results were in line with those of other research studies. Subsequently, accepting and coping with negative emotions could be addressed as fundamental elements of mental health. Many of the clinical features of the disorder are rooted in a failure to adaptively regulate undesired negative emotions. Learning to recognize emotional responses is greatly beneficial to the components of mental health; identifying the function of emotions, especially negative ones, is an essential first step toward mental health.

We also observed that ER skills training has enhanced the organizational performance in the investigated employees' performance. The obtained results highlighted that ER skills training could improve the sense of belonging to the organization by accepting the values of the organization among employees.

This study was naturally associated with some limitations, as follows: There was no follow-up stage to evaluate the stability of the achieved therapeutic results. Another limitation of the current research was the lack of performing clinical interviews along with questionnaires. Eventually, the lack of selecting subjects from different organizations was the last limitation of this study, which could have enabled us to make comparisons between the employees of various organizations. 
Individuals might have a low tendency to fill out questionnaires and might answer the questions with insufficient accuracy; thus, future investigations are recommended to conduct clinical interviews along with questionnaires. It is also suggested that in addition to exploring the influence of ER skills training on mental health, happiness, and employee performance be studied. Moreover, a follow-up phase should be considered to ensure the continuity of the effectiveness of the findings. It is also recommended that future research implement the group training of ER skills to employees, as well as subjects from different organizations.

\section{Conclusion}

Emotion regulation training could play an essential role in reducing physical symptoms, anxiety, depression, and other mental health conditions by informing a person about positive and negative emotions, as well as accepting and expressing them promptly. The present research findings highlighted the effectiveness of emotion regulation skills training on mental health, happiness, and one aspect of organizational performance in the investigated employees. Accordingly, the significance of emotion regulation skills training should be considered in improving mental health, happiness, and organizational performance among employees.

\section{Compliance with ethical standards}

\section{Acknowledgments}

The authors would like to acknowledge all of those who contributed to this work.

\section{Disclosure of conflict of interest}

The authors declared no conflicts of interest.

\section{Statement of ethical approval}

All procedures performed in the study involving human participants were in accordance with the ethical standards of the institutional and national research committee and with the 1964 Helsinki declaration and its later amendments or comparable ethical standards. The required approval was obtained from the relevant Ethics Committee prior to conducting the research. Moreover, participating in the study was voluntary, and the study results are available to the study samples upon request.

\section{Statement of informed consent}

The relevant, informed consent form was obtained from all study participants.

\section{References}

[1] Etkin, A., Büchel, C., \& Gross, J. J. The neural bases of emotion regulation. Nature reviews neuroscience, 2015; 16[11]:693-700.

[2] Koechlin, H., Coakley, R., Schechter, N., Werner, C., \& Kossowsky, J. The role of emotion regulation in chronic pain: A systematic literature review. Journal of psychosomatic research, 2018; 107:38-45.

[3] Kraiss, J. T., Peter, M., Moskowitz, J. T., \& Bohlmeijer, E. T. The relationship between emotion regulation and wellbeing in patients with mental disorders: A meta-analysis. Comprehensive psychiatry, 2020; 102:152189.

[4] Sakiris, N., \& Berle, D. A systematic review and meta-analysis of the Unified Protocol as a transdiagnostic emotion regulation based intervention. Clinical psychology review, 2019; 72:101751.

[5] Berking, M., Wupperman, P., Reichardt, A., Pejic, T., Dippel, A., \& Znoj, H. Emotion-regulation skills as a treatment target in psychotherapy. Behaviour research and therapy, 2008; 46[11]:1230-1237.

[6] Kring, A. M., \& Sloan, D. M. [Eds.]. Emotion regulation and psychopathology: A transdiagnostic approach to etiology and treatment. Guilford Press. 2009.

[7] Sloan, E., Hall, K., Moulding, R., Bryce, S., Mildred, H., \& Staiger, P. K. Emotion regulation as a transdiagnostic treatment construct across anxiety, depression, substance, eating and borderline personality disorders: A systematic review. Clinical psychology review, 2017; 57:141-163.

[8] Krueger, R. F., \& Eaton, N. R. Transdiagnostic factors of mental disorders. World Psychiatry, $2015 ; 14[1]: 27$. 
[9] Nolen-Hoeksema, S., Wisco, B. E., \& Lyubomirsky, S. Rethinking rumination. Perspectives on psychological science, 2008; 3[5]:400-424.

[10] Rottenberg, J., Gross, J. J., \& Gotlib, I. H. Emotion context insensitivity in major depressive disorder. Journal of abnormal psychology, 2005; 114[4]:627.

[11] McLaughlin, K. A., Mennin, D. S., \& Farach, F. J. The contributory role of worry in emotion generation and dysregulation in generalized anxiety disorder. Behaviour Research and Therapy, 2007; 45[8]:1735-1752.

[12] Linehan, M. M. Skills training manual for treating borderline personality disorder. Guilford Press. 1993.

[13] Linehan, M. M., Schmidt, H., Dimeff, L. A., Craft, J. C., Kanter, J., \& Comtois, K. A. Dialectical behavior therapy for patients with borderline personality disorder and drug-dependence. American Journal on Addictions, 1999; 8[4]:279-292.

[14] Lynch, T. R., Trost, W. T., Salsman, N., \& Linehan, M. M. Dialectical behavior therapy for borderline personality disorder. Annu. Rev. Clin. Psychol., 2007; 3:181-205.

[15] Clyne, C., \& Blampied, N. M. Training in emotion regulation as a treatment for binge eating: A preliminary study. Behaviour Change, 2004; 21[4]:269.

[16] Polivy, J., \& Herman, C. P. Causes of eating disorders. Annual review of psychology, 2002; 53[1]:187-213.

[17] Bydlowski, S., Corcos, M., Jeammet, P., Paterniti, S., Berthoz, S., Laurier, C., \& Consoli, S. M. Emotion-processing deficits in eating disorders. International journal of eating disorders, 2005; 37 [4]:321-329.

[18] Johnson, S. L. Mania and dysregulation in goal pursuit: A review. Clinical psychology review, 2005; 25[2]:241262 .

[19] Payne, L. A., Ellard, K. K., Farchione, T. J., Fairholme, C. P., \& Barlow, D. H. Emotional disorders: A unified transdiagnostic protocol. 2014.

[20] https://www.who.int/news-room/fact-sheets/detail/mental-health-strengthening-our-response

[21] Hu, T., Zhang, D., Wang, J., Mistry, R., Ran, G., \& Wang, X. Relation between emotion regulation and mental health: a meta-analysis review. Psychological reports, 2014; 114[2]:341-362.

[22] Linley, P. A., \& Joseph, S. Applied positive psychology: A new perspective for professional practice. Positive psychology in practice, 2004; 3-12.

[23] Peterson, C., \& Seligman, M. E. Character Strengths and Virtues: A Handbook and Classification [New York: American Psychological Association \& Oxford University Press, 2004]. Reflective Practice: Formation and Supervision in Ministry, 2012; 32.

[24] Seligman, M. E., \& Csikszentmihalyi, M. Positive psychology: An introduction. In Flow and the foundations of positive psychology [pp. 279-298]. Springer, Dordrecht. 2014.

[25] Roessler, J., \& Gloor, P. A. Measuring happiness increases happiness. Journal of Computational Social Science, 2020;1-24.

[26] Argyle, M., Martin, M., \& Crossland, J. Happiness as a function of personality and social encounters. Recent advances in social psychology: An international perspective, 1989; 189-203.

[27] Diener, E. Frequently asked questions about subjective well-being [Happiness and Life satisfaction]. Aprimer for reporters and newcomers. 2005.

[28] Otto, B., Misra, S., Prasad, A., \& McRae, K. Functional overlap of top-down emotion regulation and generation: An fMRI study identifying common neural substrates between cognitive reappraisal and cognitively generated emotions. Cognitive, Affective, \& Behavioral Neuroscience, 2014; 14[3]:923-938.

[29] Frenkel, S. J., \& Yu, K. H. Employment relations and human resource management in Asia. The Oxford handbook of Asian business systems, 2014; 383-418.

[30] Gosserand, R. H. An examination of individual and organizational factors related to emotional labor. 2003.

[31] Amstadter, A. Emotion Regulation and Anxiety Disorders, Anxiety Disorders, 2008; 22:211-221.

[32] Barlow, D. H. [Ed.]. Clinical handbook of psychological disorders: A step-by-step treatment manual. Guilford publications. 2014 . 
[33] Rotenstein, L. S., Ramos, M. A., Torre, M., Segal, J. B., Peluso, M. J., Guille, C., \& Mata, D. A. Prevalence of depression, depressive symptoms, and suicidal ideation among medical students: a systematic review and meta-analysis. Jama, 2016; 316[21]:2214-2236.

[34] Hills, P., \& Argyle, M. The Oxford Happiness Questionnaire: a compact scale for the measurement of psychological well-being. Personality and individual differences, 2002; 33[7]:1073-1082.

[35] Mennin, D. S., Heimberg, R. G., Turk, C. L., \& Fresco, D. M. Preliminary evidence for an emotion dysregulation mdel of generalized anxiety disorder. Behavior Research and Therapy, 2005: 43:1281-1310.

[36] Berking, M., Wupperman, P., Reichardt, A., Pejic, T., Dippel,A., \& Znoj, H. Emotion regulation skills as a treatment target in psychotherapy.Behavioral research and therapy, 2008; 46:1230-1237.

[37] Garnefski, n., \& Kraaij, V. Relationships between cognitive emotion regulation strategies and depressive symptoms: A comparative study of five specific samples. Personality and individual differences, 2006; 40:16591669.

[38] Brans, K., Koval, P., Verduyn, P., Lim, Y. L., \& Kuppens, P. The Regulation of Negative and Positive Affect in Daily Life.American Psychological Association, 2013; Vol. 13:No. 3.

[39] Webb, T. L., Gallo, I., Schweiger, M., Eleanor, G., peter, M., \& Sheeran, P. Effective regulation of affect: An action control perspective on emotion regulation. European Review Of Social Psychology, 2012; 23:18-143.

[40] Gratz, K. L., \& Gunderson, J. G. Preliminary data on acceptance based emotion regulation group intervention for deliberate selfharm among women with borderline personality disorder. Behav Ther; 2006; 37[1]:25-35.25. 